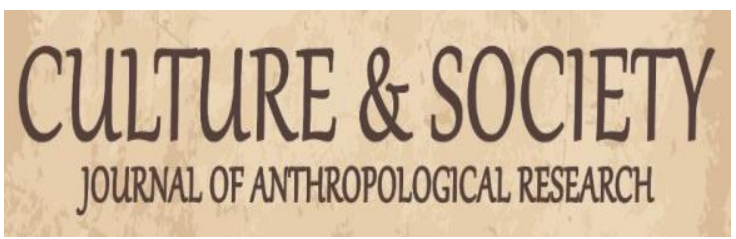

Culture \& Society: Journal of Anthropological Research

VOL. 1 NO. 4 JUNI 2020

http://culture.ppj.unp.ac.id

Email: culture@ppj.unp.ac.id

ISSN: 2686-343X (E-ISSN) 2686-3421 (P-ISSN)

DOI: https://doi.org/10.24036/csjar.v1i4.40

\title{
Respon Orang Minangkabau Terhadap Kasus Kawin Sasuku
}

\author{
Rizka Khairani ${ }^{1}$, Erda Fitriani ${ }^{2}$ \\ ${ }^{1,2}$ Universitas Negeri Padang \\ Email: rizkakhairani2009@gmail.com, fitriani_cim@fis.unp.ac.id
}

\begin{abstract}
Abstrak
Penelitian ini bertujuan untuk mendeskripsikan dan menjelaskan respon orang Minangkabau terhadap kasus kawin sasuku di Nagari Sako Utara Pasia Talang. Kawin sasuku merupakan sesuatu yang dilarang secara adat Minangkabau, akan tetapi di nagari ini kawin sasuku terjadi. Teori yang digunakan dalam menganalisis penelitian ini ialah Teori Pertukaran oleh Peter M. Blau. Metodelogi yang dipakai dalam penelitian ini ialah pendekatan kualitatif dengan menggunakan tipe studi kasus serta teknik pemilihan informan purposive sampling. Dalam pengumpulan data dilakukan dengan cara observasi, wawancara dan studi dokumen. Teknik analisis data menggunakan Miles dan Huberman. Hasil penelitian ini menunjukkan bahwa respon orang Minangkabau terhadap kasus kawin sasuku pada masyarakat Nagari Sako Utara Pasia Talang Kecamatan Sungai Pagu Kabupaten Solok Selatan yaitu : 1) Respon positif karena perilaku ini tidak dilarang dalam agama; 2) Respon positif karena perilaku ini dapat menghindari zina; 3) Respon negatif karena tidak sesuai dengan aturan adat; 4) pelaku mendapat sanksi adat berupa dikucilkan dalam masyarakat; 5) hubungan pelaku dengan warga masyarakat menjadi tidak harmonis.

Kata kunci: Adat Minangkabau, Kawin Sasuku, Orang Minangkabau, Respon Masyarakat
\end{abstract}

\section{Abstract}

The research is intended to describe and explain the Minangkabau people's response sasuku marry case at nagari north sako pasia talang. Sasuku marry is stictly prohibited by the custom on Minangkabau, and yet in nagari it happens. The theory used to analyze the study is the theory of exchange by Peter M.Blau. The methods used in this study are qualitative approaches with case studies types and purposive sampling techniques. In data collection comes observation, interview and documentation with miles and huberman's data analysis techniques. This study has shown that a public response to kawin sasuku case an nagari north sako pasia talang sungai pagu district south solok regency, disapprovally: 1) Positive response because this behavior is not restricted to religion; 2) Positive response for this behavior can avoid adultery; 3) Negative response by default; 4) perpetrators received the customary punishment of social excommunication; 5) and the perpetrators' relationship with the citizens of society became disharmony.

Keywords: Minangkabau people, Minangkabau Tradition, Public Response, Sasuku Marry

\begin{tabular}{l|l|l} 
Received: April 26, 2020 & Revised: May 21, 2020 & Published: May 22, 2020
\end{tabular}




\section{Pendahuluan}

Perkawinan dalam masyarakat Minangkabau bertujuan untuk mempertahankan keturunan melalui garis keturunan ibu atau matrilineal, yang mana perkawinan dianggap sebagai suatu peristiwa yang sangat penting. Dilihat dari fenomena kehidupan remaja sekarang yang telah merontokkan nilai-nilai adat dan nilai budaya Minangkabau sehingga terjebak dalam kehidupan bebas tanpa batas antara pergaulan laki-laki dan perempuan Minangkabau yang tidak tahu adat menyebabkan penyimpangan adat dari pergaulan bebas dan pacaran yang berakibat pada maraknya perkawinan satu suku atau kawin sasuku (Sahju, 2018). Ketidaktahuan remaja sekarang dengan adanya larangan kawin sasuku dan tentang adat istiadat yang ada di Minangkabau juga dikarenakan kurangnya sosialisasi (Atika, 2017)

Aturan adat yang ada di Minangkabau harus dipatuhi oleh masyarakat Minangkabau yang berhubungan dengan pernikahan yang biasa disebut dengan perkawinan satu suku atau kawin sasuku. Tidak hanya orang Minangkabau saja yang melarang perkawinan sasuku, namun sukubangsa lain seperti Batak juga melarang perkawinan semarga (Alpian, 2017). Begitupun dengan Nagari Sako Utara Pasia Talang yang menjadi salah satu Nagari di Kecamatan Sungai Pagu dengan kasus kawin sasuku terbanyak dari Nagari lain yang ada di Kecamatan Sungai Pagu. Melihat banyaknya kasus kawin sasuku di Nagari Sako Utara Pasia Talang yang merupakan pelanggaran adat Minangkabau, masyarakat memiliki respon yang beragam.

Beberapa penelitian mengungkapkan bahwa dampak perkawinan sasuku yaitu dibuang sepanjang adat yang sangat berpengaruh sekali terhadap kehidupan pasangan kawin sasuku di dalam lingkungan masyarakat, terutama di dalam kaum adat. Pasangan kawin sasuku akan dikucilkan dari kaum serta menerima berbagai cemoohan di lingkungan tempat tinggalnya. Faktor cinta adalah faktor pendorong utama bagi setiap individu dalam melakukan perkawinan sasuku yang semakin banyak dalam masyarakat, seiring dengan tingkat pendidikan yang semakin tinggi dengan pemikiran yang rasional dan faktor ekonomi juga menjadi alasan penyimpangan terjadi serta budaya yang semakin kuat seiring dengan perkembangan zaman. Oleh sebab itu orang tua sangat berperan penting dalam menjaga anaknya agar tidak melakukan hal yang tidak diinginkan seperti melakukan perkawinan sasuku. Apalagi perkawinan sasuku juga berdampak bagi keluarga yang pada akhirnya menjadi aib keluarga dan menjadi bahan gunjingan di tengah masyarakat (Saputri, 2015). Pada setiap daerah mempunyai tradisi serta sistem sosial yang berbeda namun bagi pelanggarnya tetap dikenakan ganjaran yang disebut sebagai sanksi, dengan adat istiadat yang sudah ada dan menjadi hukum adat setempat akan lebih kuat (Masykuri, 2016)

Melarang perkawinan sasuku merupakan ketentuan yang telah diterima secara turun temurun, namun bagi yang melakukannya sama dengan kawin satu keturunan. Maka dari itu, suku dalam kekerabatan Minangkabau menyerupai suatu Klen Matrilineal dan jodoh harus dipilih di luar suku agar tidak terjadi perkawinan sasuku (Koentjaraningrat, 1995). Begitupun dengan masyarakat di Solok Selatan salah satu daerah yang dikenal dengan daerah Saribu Rumah Gadang bisa dikategorikan daerah yang masih kental adat, namun masih ada ditemukan yang melanggar adat dan melakukan perkawinan sasuku. Berdasarkan data dari Wali Nagari, di daerah Nagari Sako Utara Pasie Talang tahun 2016-2019 terdata 8 pasang yang melakukan kawin sasuku, yaitu suku Panai, Lundang, Koto Kaciak, dan Melayu. Mereka juga berada dalam satu kampung atau nagari.

Penelitian yang relevan dengan penelitian ini adalah penelitian yang dilakukan oleh Rahmat Alpian.R yang berjudul "Kontruksi Makna Perkawinan Sasuku di Kecamatan Kuantan Mudik Kabupaten Kuantan Singingi Provinsi Riau". Penelitian ini dilakukan dengan mengkaji motif pasangan suami isteri yang melakukan pernikahan sasuku, pengetahuan dan pengalaman mereka, serta nilai-nilai yang terkandung di dalam adat istiadat larangan kawin sasuku (Alpian, 2017). Penelitian yang dilakukan oleh Helma Suryani yang berjudul "Perkawinan Sesuku Dalam Budaya Minangkabau di Nagari Batipuh Ateh (pendekatan antropologi hukum). Hasil penelitian

Culture \& Society: Journal of Anthropological Research Vol. 1, No. 4, Th. 2020 
ini adalah bahwa masyarakat Batipuh Ateh membolehkan perkawinan sesuku dengan catatan pasangan berada di Nagari yang berbeda, namun tidak membolehkan perkawinan sesuku yang tinggal atau berasal dari nagari yang sama (Helma, 2019).

Penelitian yang dilakukan Yossi Febrina yang berjudul "Perkawinan Sesuku di Nagari Jawi-Jawi Sumatera Barat Ditinjau Dari Hukum Islam". Membahas tentang analisa masalah terhadap norma-norma atau aturan hukum adat Minangkabau, yaitu larangan melangsungkan perkawinan bagi mereka yang sesuku. Hasil penelitian ini mengenai perkawinan satu suku di Minangkabau ternyata sama sekali adat dan agama tidak ada pertentangan, bahkan adat dan agama sejalan memberikan larangan terhadap perkawinan sesuku. Seandainya hukum Islam bertentangan dengan hukum adat, maka hukum Islam harus didahulukan, artinya hukum Islamlah yang akhirnya harus dijadikan titik tolak (Febrina, 2011). Penelitian Masdir Manto yang berjudul "Persepsi Masyarakat Terhadap Kawin Sesuku Di Desa Pulau Busuk Kecamatan Inuman Kabupaten Kuantan Singingi". Hasil penelitian ini adalah persepsi masyarakat terhadap kawin sesuku di Desa Pulau Busuk adalah negatif dimana mereka berpendapat bahwa kawin sesuku adalah kurang baik. Hanya $10.2 \%$ dari responden yang mempunyai persepsi yang baik terhadap kawin sesuku. Mereka yang menolak atau kurang setuju dengan kawin sesuku adalah dengan alasan kepentingan sosial dan kepentingan adat, mereka berpendapat bahwa perkawinan sesuku atau larangan kawin sesuku merupakan amanah adat dan kalau terjadi pelanggaran akan menimbulkan perasaan yang tidak nyaman dalam masyarakat (Manto, 2010).

\section{Metode Penelitian}

Penelitian mengenai respon orang Minangkabau terhadap kasus kawin sasuku berlokasi di Nagari Sako Utara Pasia Talang Kecamatan Sungai Pagu Kabupaten Solok Selatan. Alasan penulis melakukan penelitian di Nagari Sako Utara Pasia Talang ialah merupakan salah satu daerah yang melarang masyarakatnya kawin sasuku, namun fenomena kawin sasuku yang melanggar adat Minangkabau masih dilakukan anggota masyarakat.

Penelitian dilakukan dengan pendekatan kualitatif. Penelitian kualitatif ini salah satu prosedur penelitian yang menghasilkan data deskriptif berupa ucapan atau tulisan perilaku orang-orang yang diamati (Rahmat, 2009). Pemilihan informan ditentukan sumber data dengan mempertimbangkan terlebih dahulu, bukan diacak artinya menentukan informan sesuai dengan kriteria terpilih yang relevan dengan masalah penelitian, khususnya mengenai respon orang Minangkabau terhadap kasus kawin sasuku di Nagari Sako Utara Pasia Talang Kecamatan Sungai Pagu Kabupaten Solok Selatan.

Jenis penelitian yang digunakan adalah studi kasus (case study) yaitu penelitian yang memusatkan perhatian pada fenomena-fenomena sosial umum yang nyata dalam kehidupan masyarakat. Metode ini menelaah mengenai suatu keadaan masyarakat yang dilihat dari persoalan atau kasus tertentu, baik dalam lembaga, kelompok maupun individu (Syani, 2007). Dalam penelitian ini, penulis berusaha untuk menjelaskan bagaimana respon orang Minangkabau terhadap kasus kawin sasuku. Pemilihan informan pada penelitian ini menggunakan cara tertentu guna mendapatkan informan sesuai dengan kriteria yang penulis teliti. Adapun jumlah informan dalam penelitian ini yaitu 17 orang.

Teknik observasi yang dilakukan yaitu observasi partisipasi pasif yang mana peneliti datang ke tempat kegiatan orang yang diamati tetapi tidak ikut terlibat dalam kegiatan tersebut. Observasi dilakukan dengan mengambil secara langsung data dari masyarakat yang menjadi subjek yang diteliti (Burhan, 2007). Hal ini dilakukan untuk memperoleh data yang didapatkan dari hasil wawancara dan data mentah dari kantor wali nagari, akan tetapi penulis tidak melibatkan diri dalam kegiatan tersebut. Wawancara yang dilakukan oleh penulis yaitu wawancara mendalam. Wawancara mendalam merupakan teknik pengumpulan data yang mempertemukan dua orang untuk bertukar informasi dan ide melalui tanya jawab, sehingga dapat dikonstruksikan makna dalam satu topik tertentu (Sugiyono, 2009). Melalui wawancara

Culture \& Society: Journal of Anthropological Research Vol. 1, No. 4, Th. 2020 
mendalam secara tatap muka, maka penulis akan mendapatkan data mengenai permasalahan yang ingin diteliti oleh penulis.

Supaya data yang penulis peroleh dalam penelitian akurat, valid dan sah. Maka dilakukan dengan teknik triangulasi data. Data yang sama dikumpulkan dari objek yang berbeda. Hal ini bertujuan untuk pengecekan atau pembanding terhadap data yang sudah di peroleh peneliti (Ghony \& Fauzan, 2016). Teknik analisis yang digunakan yaitu teknik analisis data dari Miles dan Huberman.

\section{Hasil dan Pembahasan}

\section{Respon Orang Minangkabau terhadap Kawin Sasuku}

Fenomena kawin sasuku yang terjadi di Nagari Sako Utara Pasia Talang Kecamatan Sungai Pagu Kabupaten Solok Selatan, secara tradisional dan secara adat masyarakat yang menganggap perkawinan sasuku merupakan hal yang tabu. Pada dasarnya masyarakat di Nagari Sako Utara Pasia Talang masih hidup dalam kekentalan adat istiadat Minangkabau. Namun dengan terjadinya beberapa kasus kawin sasuku di Nagari Sako Utara Pasia Talang, dan perubahan-perubahan yang terjadi pada masyarakat sekitarnya saat ini, masyarakat memberikan respon yang beragam terhadap fenomena tersebut. Pada dasarnya kawin sasuku yang merupakan larangan adat Minangkabau terjadi di Nagari Sako Utara Pasia Talang.

Salah satu kasus yang terjadi yaitu pada kasus Sh dan Ib yang telah ditentang oleh kedua orang tua dan mamak-mamaknya. Mamak dari Sh sudah berkali-kali mengingatkan pada Ib untuk tidak menghubungi keponakannya lagi, namun karena mereka tetap ingin menikah dan telah menjadi bahan gunjingan di sekitar lingkungan tempat tinggal orang tua Sh.orangtua Sh pun juga sudah mengingatkan bahwa semua yang terjadi antara Sh dan Ib adalah hal yang salah dalam adat Minangkabau, mereka sempat melarikan diri dan menikah di daerah lain sampai akhirnya orang tua Sh tidak berani ke luar rumah untuk bertemu dengan tetangga, karena jika bertemu tetangga selalu mengulik-ngulik hal yang terjadi pada keluarga Sh dengan nada mengejek dan wajah yang seolah bahagia di atas penderitaan orang lain. Sejak saat itu orang tua Sh tidak mengikuti kegiatan sosial masyarakat lagi karena malu dan juga sudah dianggap tak pandai dalam mendidik anak. Bahkan kasus Sh dan Ib ini sempai sengaja diceritakan di radio yang bertujuan untuk memberikan sanksi sosial dan efek jera namun penyiaran tersebut tidak berlangsung lama.

Berdasarkan dari penelitian yang telah dilakukan ada beberapa respon yang didapat dari masyarakat, masing-masing alasan dan penjabarannya sebagai berikut:

\section{Tidak Dilarang dalam Agama}

Penyataan masyarakat yang merespon perkawinan sasuku sebagai hal yang wajar, salah satunya karena tidak dilarang dalam agama. Dari perkawinan diharamkan untuk dinikahi menurut hukum Islam tidak disebutkan adanya larangan perkawinan sasuku. Pernyataan ini sesuai dengan yang disampaikan oleh salah satu kerabat atau bisa disebut dengan mamak dari pelaku kawin sasuku berikut penuturannya yaitu "mau gimana lagi, mungkin mereka sudah jodoh kalau melarang pun nanti terjadi yang tidak-tidak, kalau diagama tidak melarang dan menurut saya tidak apa-apa jika ada yang kawin sasuku". Jika dikaitkan dengan teori pertukaran, respon yang didapat akibat tidak adanya larangan agama memang benar adanya. Kesepakatan bersama yang diambil oleh pihak keluarga digunakan sebagai media kehidupan sosial dan sebagai mata rantai yang menghubungkan transaksi sosial. Pertukaran sosial yang terjadi tak langsung menentukan proses integrasi dan diferensiasi didalamnya.

Sama halnya dengan salah seorang orang tua yang sudah memberi restu pada anaknya untuk kawin sasuku, yaitu ibu Sap, beliau menyebutkan bahwa hubungannya dengan anak dan menantu baik-baik saja, meskipun hubungan dengan tetangga dan masyarakat setempat sempat 
tidak berbaikan, karena ibu Sap menyadari bahwa kawin sasuku ini tidak dilarang dalam agama Islam.

\section{Menghindari Zina}

Zina adalah salah satu keburukan yang nyata berakibat pada kerusakan diri dari orang yang melakukannya dan juga masyarakat secara luas, zina juga termasuk dosa besar dalam Islam. Pergaulan remaja sekarang ini yang tidak paham mengenai adat istiadat dan agama juga menyebabkan terjadinya perzinahan. Adanya remaja yang berpacaran maka orang tua memiliki ketakutan, tidak hanya itu, remaja di Minangkabau menjalin hubungan dengan orang yang satu suku. Hubungan yang terjalin antara satu sama lain menyebabkan ketakutan tersendiri bagi orangtua baik dari pandangan agama maupun pandangan adat. Untuk menghindari zina yang akan terjadi maka orang tua dari pasangan menganggap tidak masalah untuk melakukan kawin sasuku karena semua dilakukan agar tidak terjadi hal-hal yang tidak diinginkan.

Seperti yang disampaikan oleh orang tua dari salah satu pelaku kawin sasuku, berikut penuturannya "kawin sasuku kalau menurut saya memang salah awalnya, karena saya orang Minangkabau yang hidup beradat jadi saya harus mengikuti adat. Tetapi karena anak saya sudah berpacaran dengan orang yang awalnya saya tidak tahu jika kami sasuku. Ternyata mereka sudah menjalin hubungan lumayan lama dan saya baru tahu jika sukunya sama. Disini saya sudah mencoba memisahkan mereka tetapi semua tidak ada hasilnya dan mereka tetap bersikeras untuk menjalin hubungan sampai ketahap pernikahan. Karena saya takut jika mereka melakukan hal yang tidak diinginkan seperti berzina maka saya membujuk ayahnya untuk merestui hubungan mereka meski ayahnya sampai sekarang masih belum bisa menerima. Yang saya takutkan hanya anak saya yang mendekati zina, biar saja saya nikahkan meskipun sasuku, saya terima apapun perkataan orang sekampung mengenai saya". Dalam penelitian yang penulis lakukan, respon masyarakat yang setuju dengan perkawinan sasuku salah satunya dengan menghindari perbuatan zina sesuai dengan penyataan yang disampaikan pada saat penulis melakukan wawancara di lapangan.

\section{Tidak Sesuai dengan Adat}

Perkawinan sasuku merupakan suatu hal yang dilarang dan bisa dikatakan tidak sesuai dengan adat. Masyarakat Minangkabau hendaknya patuh dan mengikuti petuah adat yang sejak dahulu diberlakukan. Memang tidak dilarang dalam ajaran agama Islam dan bisa dikatakan masih sesuai dengan ajaran agama Islam, namun bagi masyarakat Minangkabau yang beradat jelas hal tersebut tidak sesuai. Masyarakat yang telah lahir dan hidup sebagai orang Minang tentu harus mengikuti adat yang berlaku. Begitu juga aturan adat Minangkabau yang masih berlaku di Ngarai Sako Utara Pasia Talang. Aturan adat ini memang harus dipatuhi dan ditaati bagi masyarakat Minangkabau, namun masih ada yang melanggarnya, salah satunya dengan kawin sasuku.

Kawin sasuku yang merupakan salah satu tindakan atau perbuatan yang tidak sesuai dengan adat Minangkabau. Pada umumnya masyarakat yang ada di Nagari Sako Utara Pasia Talang Memberikan respon tidak setuju dangan adanya kawin sasuku karena kawin sasuku hal yang tidak sesuai dengan adat. Hal ini disampaikan dalam wawancara dengan salah seorang tokoh adat berikut penuturannya "kawin sasuku yang saya tahu dari dahulu sampai sekarang memang sasuatu yang sangat salah untuk keluarga maupun kaum adat. Karena kawin sasuku tidak sesuai dengan adat kita. Hal tersebut merupakan pelanggaran adat. Kita hidup di daerah yang kental dengan adat, seharusnya kita mengikuti aturan adat setelah mengikuti perintah agama, jika bukan untuk kebaikan tidak mungkin adat ada dan dilestarikan hingga sekarang".

\section{Dikucilkan oleh Masyarakat}

Adanya larangan kawin sasuku tetapi masyarakat masih tetap melakukan pelanggaran adat. Hal ini menyebabkan hubungan antar individu atau kelompok di masyarakat menjadi 
terganggu dengan dikucilkannya pasangan yang kawin sasuku bahkan juga mengucilkan keluarga dari pasangan yang kawin sasuku. Dikucilkan dalam masyarakat yaitu tidak diikutsertakan dalam kegiatan bermasyarakat baik itu berupa kabar baik atau kabar buruk, kabar baik atau kabar buruk yang dimaksud disini seperti kematian atau perhelatan perkawinan dan perhelatan adat lainnya yang tidak akan mengikut sertakan orang yang melakukan pelanggaran adat seperti kawin sasuku.

Hal ini juga di pertegas dengan penuturan salah seorang kerabat dari pasangan yang kawin sasuku, berikut penuturannya "sebelum ada kasus kawin sasuku ini, kami dipandang baik oleh orang-orang, tetapi semenjak kawin sasuku terjadi pada cucu saya, semua orang nagari menggunjingkan bahkan mengucilkan kami sekeluarga. Pada sewaktu-waktu kegiatan wirid di Masjid saya merasa diasingkan dan dikucilkan oleh teman-teman wirid. Rumah kami sepi dan kami pun menutup diri dari masyarakat karena kami tahu kalau keluarga kami dikucilkan masyarakat setempat. Bahkan rumah kami sepi, tidak ada saudara atau masyarakat membawa kami sekeluarga dalam bermasyarakat lagi". Maka yang berdampak pada peristiwa ini bukan hanya pasangan yang kawin sasuku, namun juga berdampak pada kerabat dari pasangan yang kawin sasuku. Dengan demikian kedudukan kita di dalam masyarakat sudah tidak ada.

\section{Hubungan Menjadi Tidak Harmonis}

Perkawinan menimbulkan hubungan baru tidak hanya antara individu namun juga kepada kedua keluarga dan memperoleh keserasian atau keharmonisan antar keluarga (Amir M.S, 2001). Hubungan yang semula baik-baik saja bisa sewaktu-waktu hancur akibat perbuatan yang seharusnya tidak terjadi. Hal ini terjadi pada orang yang kawin sasuku di Nagari Sako Utara Pasia Talang. Tidak hanya hubungan antar keluarga saja yang rusak, namun juga hubungan bermasyarakat. Keluarga yang semula berpihakpun akan meninggalkan jika perbuatan yang dilakukan adalah perbuatan yang salah. Meskipun kasus kawin sasuku mendapatkan respon yang tidak setuju, masih saja terjadi dan berakibat pada hubungan sosial yang menjadi tidak harmonis antar individu maupun kelompok.

Seperti pada kasus FD yang merupakan pelaku kawin sasuku yang melakukan wawancara dengan penulis, berikut penuturan dari FD "saya memohon pada orang tua saya untuk menikah dengan pasangan yang saya pilih. Tapi karena kita sasuku, makanya hubungan saya ditentang oleh orang tua saya. Saya melawan orang tua sampai-sampai saya diusir dari rumah. Semenjak kejadian itu orang tua saya tidak mau tahu apapun yang terjadi di kehidupan saya. Saya merasa hubungan saya dengan keluarga besar dari orang tua saya tidak baik lagi. Saya merasa dibuang oleh orang tua saya padahal semua yang terjadi akibat dari perbuatan yang saya lakukan. Sampai sekarang pun hubungan kami belum membaik dan hubungan saya dan masyarakat pun menjadi tidak baik. Akibat dari permasalahan kawin sasuku yang saya lakukan, mamak saya yang merupakan adik dari mama saya juga tidak pernah lagi mengunjungi rumah kakaknya akibat perbuatan saya, hubungan mamak dan kakak saya pun menjadi tidak harmonis akibat kasus kawin sasuku yang saya lakukan".

Orang tua FD menyampaikan langsung pada suami FD bahwa dia tidak akan mendapatkan tempat di rumah orang tua FD karena menganggap bahwa semua yang terjadi disebabkan oleh anak dan menantunya sampai menyebabkan hubungan ibu FD tidak baik dengan adik kandungnya. Meski mereka tinggal berdekatan suami dari FD tak pernah diperkenakan masuk ke dalam rumah orangtuanya bahkan jika ada acara keluarga sekalipun suami dari FD tak diajak dan diikutsertakan.

\section{Analisa Respon Orang Minangkabau terhadap Kawin Sasuku}

Tujuan dari teori pertukaran adalah untuk memahami sturktur sosial berdasarkan analisis proses sosial yang mempengaruhi hubungan antara individu dan kelompok. Proses pertukaran yang mengatur kebanyakan perilaku manusia melandasi hubungan antar-individu

Culture \& Society: Journal of Anthropological Research Vol. 1, No. 4, Th. 2020 
maupun antar-kelompok. Proses pertukaran antar pribadi yang mengarah pada struktur sosial ke perubahan sosial, dibayangkan olehnya, telah didorong oleh serangkaian empat tahap yaitu, langkah pertama ialah transaksi-transaksi pertukaran antar pribadi akan menghasilkan suatu reward (penghargaan) ketidakpuasan. Langkah kedua adalah diferensiasi status atau kekuasaan sebagai akibat oleh apa yang dihasilkan pada langkah pertama. Langkah ketiga adalah legitimasi dan organisasi sebagai akibat dari langkah sebelumnya dan akan mendorong langkah berikutnya. Langkah terakhir adalah adanya perlawanan dan perubahan (Ritzer, 2014)

Jika dikaitkan dengan penelitian transaksi pertukaran antar pribadi akan menghasilkan suatu reward atau ketidakpuasan, reward disini bukan hanya berupa penghargaan namun kekecewaan atau rasa hormat yang semula ada dalam diri seseorang namun hilang dan ditukarkan dengan hal yang mengecewakan akibat perbuatan yang dilakukan dan dipandang buruk oleh masyarakat. Akibat dari kawin sasuku yang dilakukan kedudukan dalam masyarakat pun menjadi tak berarti. Yang semula hidup damai dalam masyarakat dan kaum adat yang berada dalam satu rumah gadang yang sama namun sudah tidak dapat dirasakan lagi dan harus mengakui dan tidak bisa merasakan hadir dalam kelompok tersebut karena sudah adanya perubahan dari perbuatan yang terjadi pada diri individu itu sendiri yaitu dengan melakukan kawin sasuku maka terjadi perlawanan dan perubahan terhadap individu yang melakukannya dalam kehidupan bermasyarakat.

Pada penelitian yang dilakukan respon masyarakat banyak yang menolak hadirnya pasangan yang kawin sasuku karena dianggap sudah melanggar ketentuan adat yang berlaku di Minangkabau. Perubahan struktur sosial pun sempat dilakukan karena salah satu kasus yang sudah lama terjadi, namun untuk kasus yang penulis teliti tidak ada perubahan pada struktur sosial, hanya saja kedudukan sosial semula dihormati dalam masyarakat menjadi tidak lagi dihormati karena kasus kawin sasuku yang tejadi.

\section{Kesimpulan}

Berdasarkan hasil penelitian yang telah penulis lakukan di lapangan dapat disimpulkan bahwa respon masyarakat terhadap kasus kawin sasuku d tidak baik terlihat dari sebagian besar masyarakat yang penulis temukan memberikan jawaban yang sama yaitu tidak setuju dengan adanya kasus kawin sasuku. Meskipun terdapat beberapa masyarakat yang merespon baik mengenai kawin sasuku. Bentuk respon masyarakat yang setuju dengan adanya kawin sasuku yaitu tidak dilarang dalam agama, dengan pernyataan masyarakat yang menyebutkan bahwa kawin sasuku tidak dilarang dalam agama menyebabkan masyarakat memberikan respon setuju. Respon setuju lainnya yaitu manghindari zina, demi menghindari perbuatan zina antara pasangan yang kawin sasuku, melakukan perkawinan merupakan hal yang dianggap wajar-wajar saja. Respon yang tidak setuju yaitu tidak sesuai dengan adat hal tersebut disampaikan oleh masyarakat yang tidak setuju karena hidup di tengah lingkungan yang beradat. Dikucilkan oleh masyarakat juga salah satu respon yang tidak setuju agar tidak terjadi lagi kasus perkawinan sasuku. Hubungan menjadi tidak harmonis merupakan respon tidak setuju masyarakat terhadap pasangan yang kawin sasuku karena perbuatan yang dilakukan menyebabkan hubungan antar individu dan kelompok menjadi tidak baik

\section{Daftar Pustaka}

Alpian, R. (2017). Kontruksi Makna Perkawinan Sasuku di Kecamatan Kuantan Mudik Kabupaten Kuantan Singingi Provinsi Riau. Journal Online Mahasiswa FISIP, 4(1), 1-10.

Amir M.S. (2001). Adat Minangkabau Pola dan Tujuan Hidup Orang Minang. Jakarta : PT. Mutiara Sumber Widya.

Atika, D. (2017). Persepsi Masyarakat Minangkabau Terhadap Pernikahan Sesuku di Nagari Muaro. Tesis. Universitas Pendidikan Indonesia

Culture \& Society: Journal of Anthropological Research Vol. 1, No. 4, Th. 2020 
Burhan, B. (2007). Penelitian Kualitatif: Komunikasi, Ekonomi, Kebijakan Publik, dan Ilmu Sosial Lainnya. Jakarta: Fajar Interpratama.

Febrina, Y. (2011). Perkawinan Satu Suku di Nagari Jawi-Jawi Sumatera Barat Ditinjau dari Hukum Islam. Skripsi. UIN Syarif Hidayatullah

Ghony, M. D., \& Fauzan, A. (2016). Metodologi Penelitian Kualitatif. Yogyakarta: Ar-Ruzz Media.

Koentjaraningrat, K. (1995). Manusia dan Kebudayaan di Indonesia. Jakarta: Djambatan.

Manto, M. (2010). Persepsi Masyarakat Terhadap Kawin Sasuku di Desa Pulau Busuk Kecamatan Inuman Kabupaten Kuantan Singingi. Skripsi. UIN Sultan Syarif Kasim Riau

Masykuri, S. (2016). Larangan Pernikahan Sesuku Pada Suku Melayu dalam Perspektif Hukum Islam (Studi Kasus di Kecamatan Perhentian Raja Kabupaten Kampar Provinsi Riau. Skripsi. UIN Salatiga.

Ritzer, G. (2014). Teori Sosiologi Modern (7 ed.; Triwibowo B.S, Ed.). Depok: Prenadamedia Group.

Sahju, A. H. (2018). Larangan Perkawinan Sesuku Pada Masyarakat Hukum Adat Suku Jambak Padang-Pariaman di Bandar Lampung. Skripsi. Universitas Negeri Lampung

Saputri, M. D. (2015). Perkawinan Sesuku di Desa Tanjung Kecamatan Koto Kampar Hulu Kabupaten Kampar. Jurnal Online Mahasiswa FISIP, 2(2), 44-51. https://doi.org/10.1017/ CBO9781107415324.004

Sugiyono, S. (2009). Metode Penelitian Kuantitatif, Kualitatif, Dan R\&D. Bandung: Alfabeta.

Helma, S. (2019). Perkawinan Sesuku Dalam Budaya Minangkabau di Nagari Batipuh Ateh (Pendekatan Antropologi Hukum). Skripsi. UIN Syarif Hidayatullah Jakarta.

Syani, A. (2007). Sosiologi (Skematika, Teori, dan Terapan). Jakarta: PT. Bumi Aksara. 